\title{
Investigating Energy-Related Occupants' Behaviors on Energy Consumption in Residential Buildings (Opening/Closing Windows and Blinds)
}

\author{
Shima Molavi Sanzighi \\ Department of Architecture, Gonbad Kavoos Branch, Islamic Azad University, Gonbad Kavoos, Iran \\ Email address: \\ Shima.molavi@yahoo.com \\ To cite this article: \\ Shima Molavi Sanzighi. Investigating Energy-Related Occupants' Behaviors on Energy Consumption in Residential Buildings \\ (Opening/Closing Windows and Blinds). Journal of Energy and Natural Resources. Vol. 7, No. 1, 2018, pp. 32-39. \\ doi: $10.11648 /$ j.jenr.20180701.15
}

Received: March 31, 2018; Accepted: June 12, 2018; Published: June 20, 2018

\begin{abstract}
Considering the high energy consumption in the building sector, there are several ways to improve energy consumption, part of which is technology-related and partly related to the performance of the people, given that the human segment is much easier and cheaper than the technology sector., The optimal use of these energy-driven behaviors can greatly help improve indoor comfort and reduce energy consumption in the building. In this research, the effects of changes in the energy-oriented behavior pattern (opening and closing of the window and curtain) on the cooling load and power consumption are reviewed annually in a common building. Building simulation was done using the Designer Bidder software. It was found that the use of a proper behavior pattern could reduce the percentage of energy consumption (electricity for cooling). After choosing a residential building in the Gonbad-e-Kavos, a typical apartment building in the city, simulations have been carried out in three modes, and the cooling and electricity consumption (purely for cooling) models are compared in one year. In the simulated model, the third state behavioral model was more favorable in terms of reducing cooling load and power consumption in one year. The results of this simulation show that a change in behavior patterns can make a significant change in its energy consumption. Energy-efficient behaviors have a very high potential for optimizing energy consumption in buildings along with other engineering and technical solutions.
\end{abstract}

Keywords: Energy-Related Behavior, Reducing Energy Consumption, Thermal Comfort, Design Builder Software, Residential Building

\section{Introduction}

Today, buildings account for the largest share of energy consumption, both at the local and global levels [1]. Energy demand in the building sector is equal to $34 \%$ of the world's energy consumption, a figure which is more than the demand in the industry and transportation sectors [2]. In addition to the increased risk of quick finish of fossil fuels, energy consumption growth in today's societies has put the world at the risk of threatening changes [3]. According to recently researches the residential sector is a substantial consumer of energy in every country, so focusing on the amount of energy consumption in residential sector is imperative issue $[3,4]$. Due to the population growth, increased housing construction, and increased investment in this sector in recent years, residential buildings households play an important role in energy consumption either directly or indirectly with the decision the make [5]. Energy consumption in Iran is considerably higher than global standards, mainly because of the unfavorable condition of buildings in terms of energy consumption [6]. Hence, the application of appropriate strategies to reduce energy consumption, especially in buildings with continuous use, can greatly contribute to the conservation of existing resources [3]. Although apartments are one of the most common types of building in Asia [7] and given that technology alone does not guarantee energy savings in buildings, realization of energy conservation is a challenge 
that is both partly technical and partly dependent on human performance [8]. Apart from the technological and technical section that has its own issues and complexities, the human part actually involves the activities and behavior of inhabitants. In fact, this part is not as complex as the technological section. In addition, it is less expensive and consists of behavioral changes that can affect energy consumption. The interaction of residents with building systems mainly aims to achieve thermal, visual, acoustic, and conditioning comfort [9]. It is important to note that energy-related behavior of residents in a building is considered the main factor affecting the energy consumption. On the other hand, behavioral solutions are less expensive and have a high potential to reduce energy consumption in buildings [10]. One of the behaviors that take place in the building to achieve this is the opening and closing the windows and the use of curtains. The window is one of the outer walls that has a remarkable impact on energy consumption as well as thermal comfort [4]. This behavior, called energy-related behavior, has a clear impact on the energy consumption of the building. In addition, energy-related behaviors greatly affect the energy efficiency gap, both potentially and actually [11]. Except opening and closing the window and the use of curtains, other energyrelated behaviors include turning on and off the light, turning on and off the cooling and heating systems, and spatial displacement (presence and absence in space) [12]. This research focuses on the specific energy related behavior (opening and closing window/blind) as passive strategy, and its potential application for improving indoor thermal comfort and energy efficiency in residential buildings.

\section{Method}

\subsection{Theatrical Foundation}

One of the most important barriers to the improvement of energy efficiency in buildings is the lack of knowledge and awareness about the behavior of residents in a building. Energy consumption in a building is influenced by many factors such as building linings, climate, cooling and heating systems, air conditioning, and behavior and activities of the residents. As previous studies show, different behavioral patterns lead to different levels of energy consumption in buildings [13]. Residents' behavior has a remarkable impact on energy consumption in buildings. This indicates that energy-related behaviors have a great impact on energy consumption. Studies have shown that about $10-20 \%$ of energy consumption can be reduced by changing the energyrelated behavior of residents [14]. The energy-related behavior of residents is an expression of their confrontation with the building system in order to control indoor temperature and achieve thermal, visual, and acoustic comfort inside the building [15]. The window opening and closing is one of the energy-related behaviors which has a considerable impact on indoor temperature, thermal comfort, and energy consumption in residential homes. This behavior can occur for various reasons such as internal and external temperature changes and behavioral habits [16]. The main objective of the present research is to study the effects of changes in the pattern of the window opening and closing and the use of curtain on energy consumption reduction in residential buildings. In fact, this research seeks to study the effect of energy-related behaviors on energy consumption. Figure 1 depicts a schematic view of the research theoretical foundations.

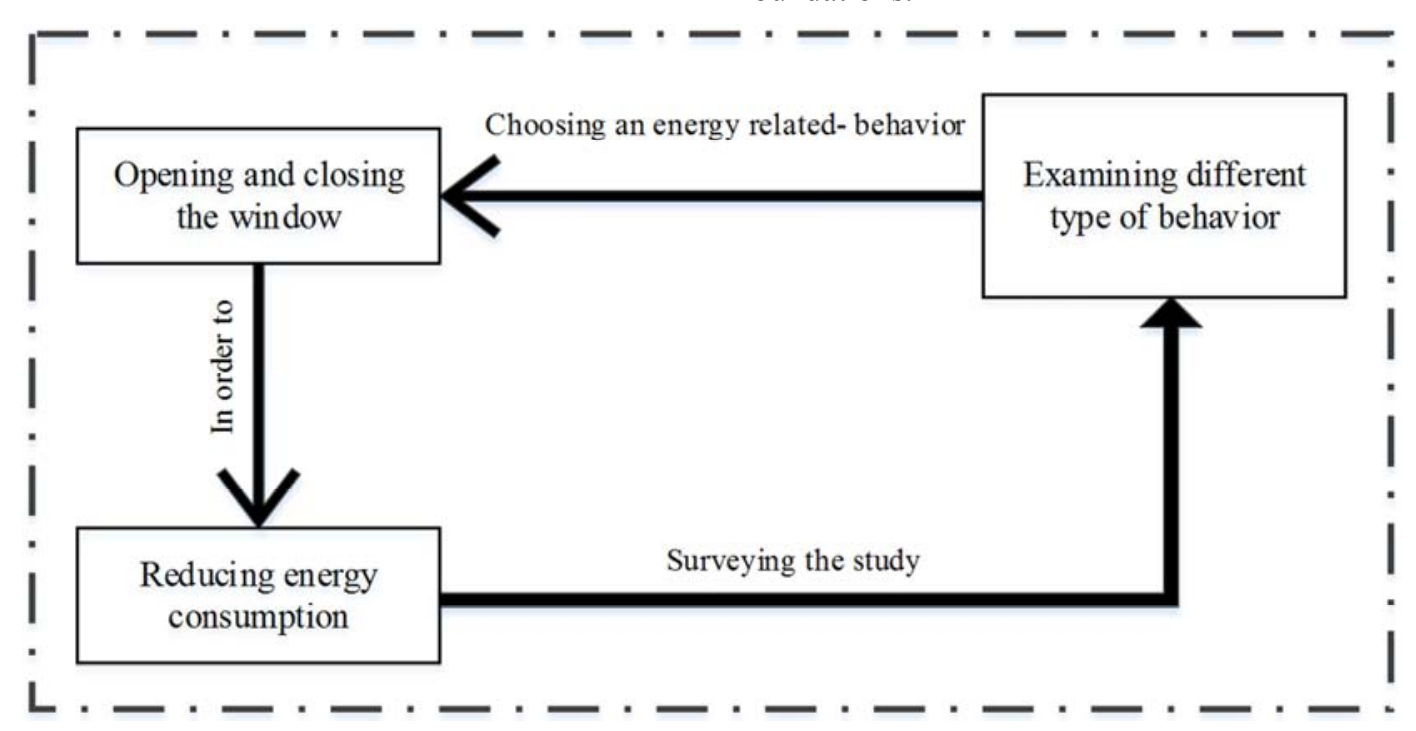

Figure 1. Pattern of theoretical foundations studied.

\subsection{Research Background}

Because of the novelty of subject, there are a few papers and studies about energy-related behavior, especially the window opening and closing.
Kim et al. (2017) studied the behavior of residents and its impact on the reduction of total energy consumption and improvement of comfort in the building. To study the effects of behavior on thermal and visual comfort and indoor air 
quality, they used energy optimization simulation software applications. The results showed that total energy consumption in the optimal mode (when the behavior of residents is included in the simulation) substantially changes compared to the base mode. The same changes were also observed in thermal and visual comfort as well as indoor air quality. The correlation coefficient between residents' behavior and energy consumption was obtained 0.879 . This figure suggests the strong influence of residents' behavior on energy consumption in buildings [17]. In a paper published by Hong et al. (2016), residents' behavior was introduced as one of the most important and effective factors in energy consumption of buildings. They also described energyrelated behaviors and stated that the window opening and closing and the curtain function are two major energy-related behaviors that make it possible for residents to control and regulate the level of thermal and visual comfort. Finally, they simulated energy-related behaviors and studies the effects of these behaviors on energy consumption. Figure 2 shows a cycle of energy-related behaviors, which indicates the importance of these behaviors in the reduction energy consumption [18].

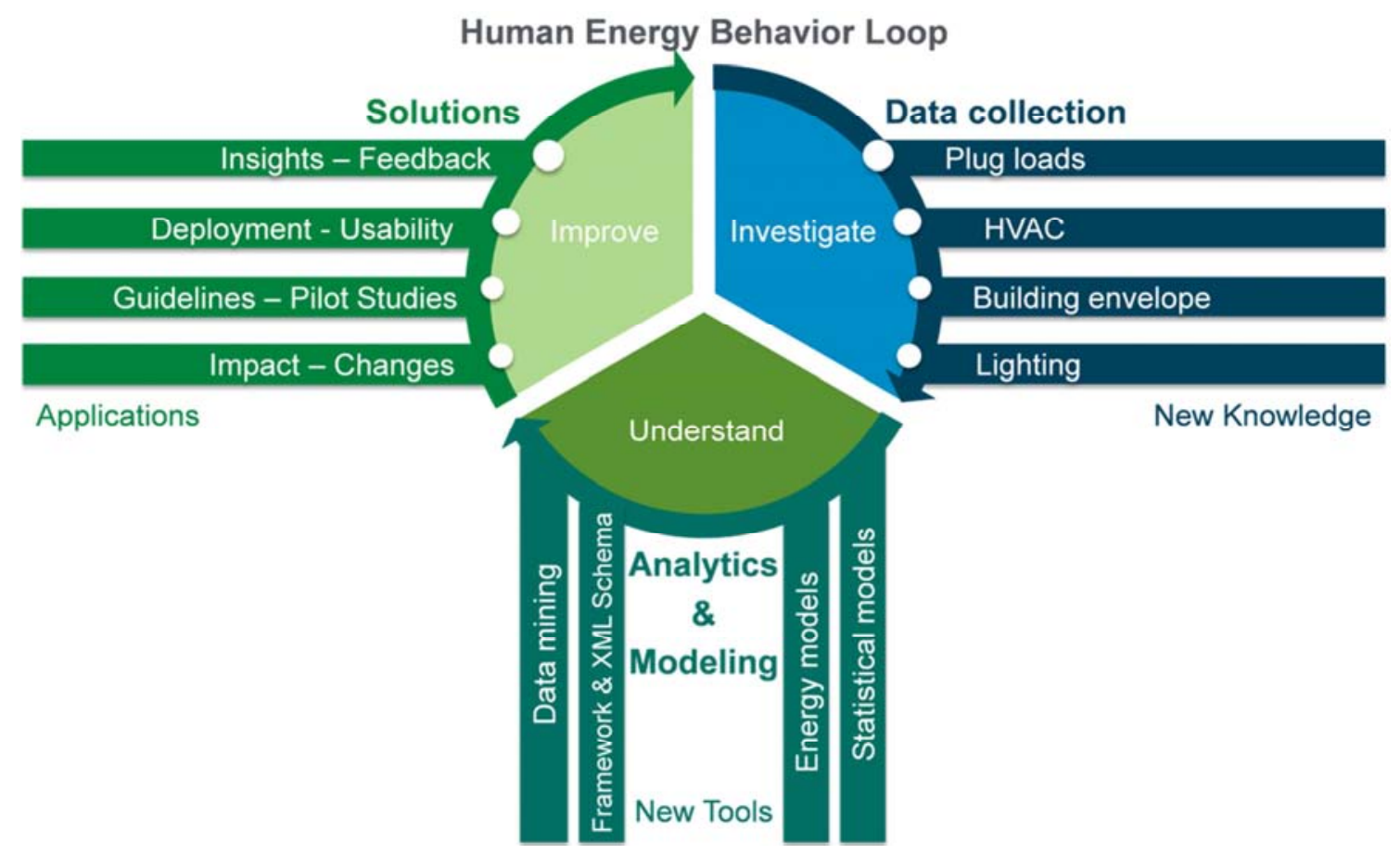

Figure 2. A Cycle of Studies on Energy-Based Behaviors (16).

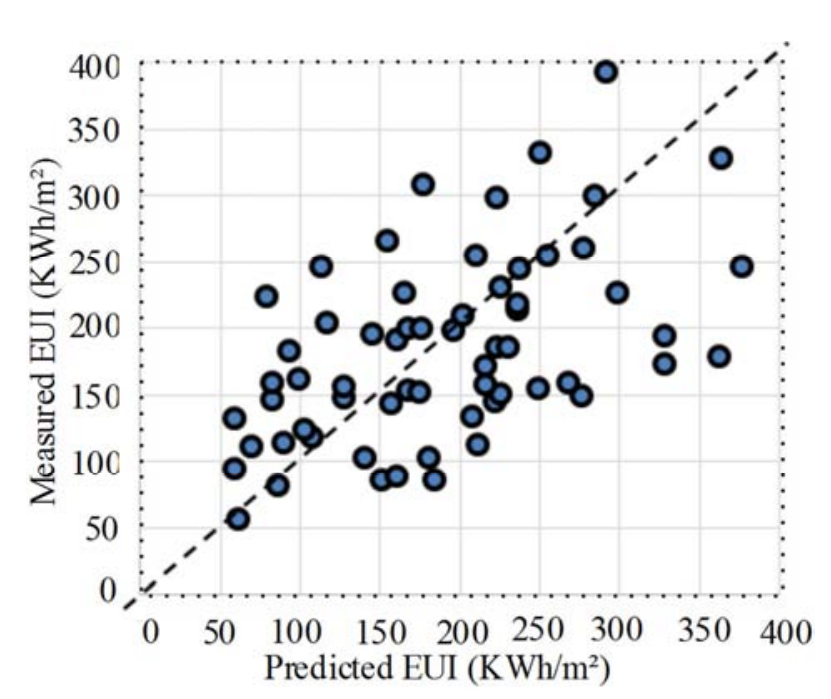

Figure 3. Comparison of measured and practiced energy use for 62 LEED construction buildings (9).

Hong et al. (2015) conducted a study in order to propose a general framework for the introduction of energy-related behaviors. Researchers believe that these behaviors are a positive and very important factor in the improvement of indoor air conditions, whereas these behaviors reduce energy consumption at a lower cost. In this study, the authors simulated 25 apartments using a software application and studied the effects of energy-related behaviors on energy consumption of these apartments in order to achieve a general framework. They concluded that taking into account these energy-related behaviors in the design and even postconstruction stages can greatly affect the energy consumption of buildings [6]. In the second part of the above-mentioned paper, Hong et al. used two samples of energy-related behaviors, including turning on the ventilation or fan coil and opening or closing the windows and curtains, for simulation and standardization. At the end, they presented the results in the form of a flexible, expandable, and consistent template to be used by designers in order to reduce a considerable amount of energy consumption before the construction of buildings [7]. Diane et al. (2015) studied the effects of energy-related behaviors on the energy performance of buildings and discussed the gaps in this regard. They evaluated energy-related behaviors of residents from different views. Accordingly, behavior can be applied to 
different equations or evaluation methods as a data unit to be qualitatively used in the process of design and simulation in order to optimize energy consumption in buildings [9]. Due to the considerable suspicion of building model inputs, simulation results deviate widely from the actual energy consumption of a building. Figure 3 shows a comparison between the simulated energy consumption and measured energy consumption for 62 leadership in energy and environmental design (LEED) certificated buildings in United States. As can been seen, in some buildings are, simulated and actual amount of energy consumption are very close, nevertheless there is an average error of $18 \%$; this error relates to the behavior of residential that effects on energy consumption (figure3) [9].

\subsection{Field Investigation: Numerical Analysis of Simulation Energy - Related Behavior}

The present research was a descriptive study, which was conducted using library studies and an energy simulation software application. Many library studies have conducted on the potentials of energy-related behaviors and their impact on energy consumption in residential buildings in different countries. Based on the library studies, among the energyrelated behaviors, the window opening and closing and shutting the curtain were selected to study their effects on energy consumption and energy efficiency improvement in residential buildings in a moderate and humid climate. Simulation of an energy-related behavior in the desired software application is a solution that provides a more accurate examination and estimation of conditions, potentials of energyrelated behaviors, and the effects of human factors [19]. On the other hand, the interaction between components of design, climate, users, and heating, ventilation, and lighting systems is very complicated and all factors affecting the energy efficiency of a building can be studied simply using the simulation. Therefore, the use of energy consumption simulation applications is necessary for analyzing the thermal and visual performance of a building. Using energy simulation in the design process, it is possible to evaluate all options and design decisions in a relatively seamless way [20]. The present research was an applied study in terms of objective. Given the multiplicity of energy simulation software applications, Design-Builder was used in the study for energy simulation because of the existence of settings for the ease of behavioral simulation in a building. After the review of energy-related behaviors and selection of the desired behaviors (the window opening and closing and shutting the curtain), energy consumption was simulated in three modes and compared with each other in order to investigate the relationship between changes in energy-related behaviors pattern and energy consumption. Finally, the results of the simulation were evaluated to make the ultimate conclusion.

\section{Research Process}

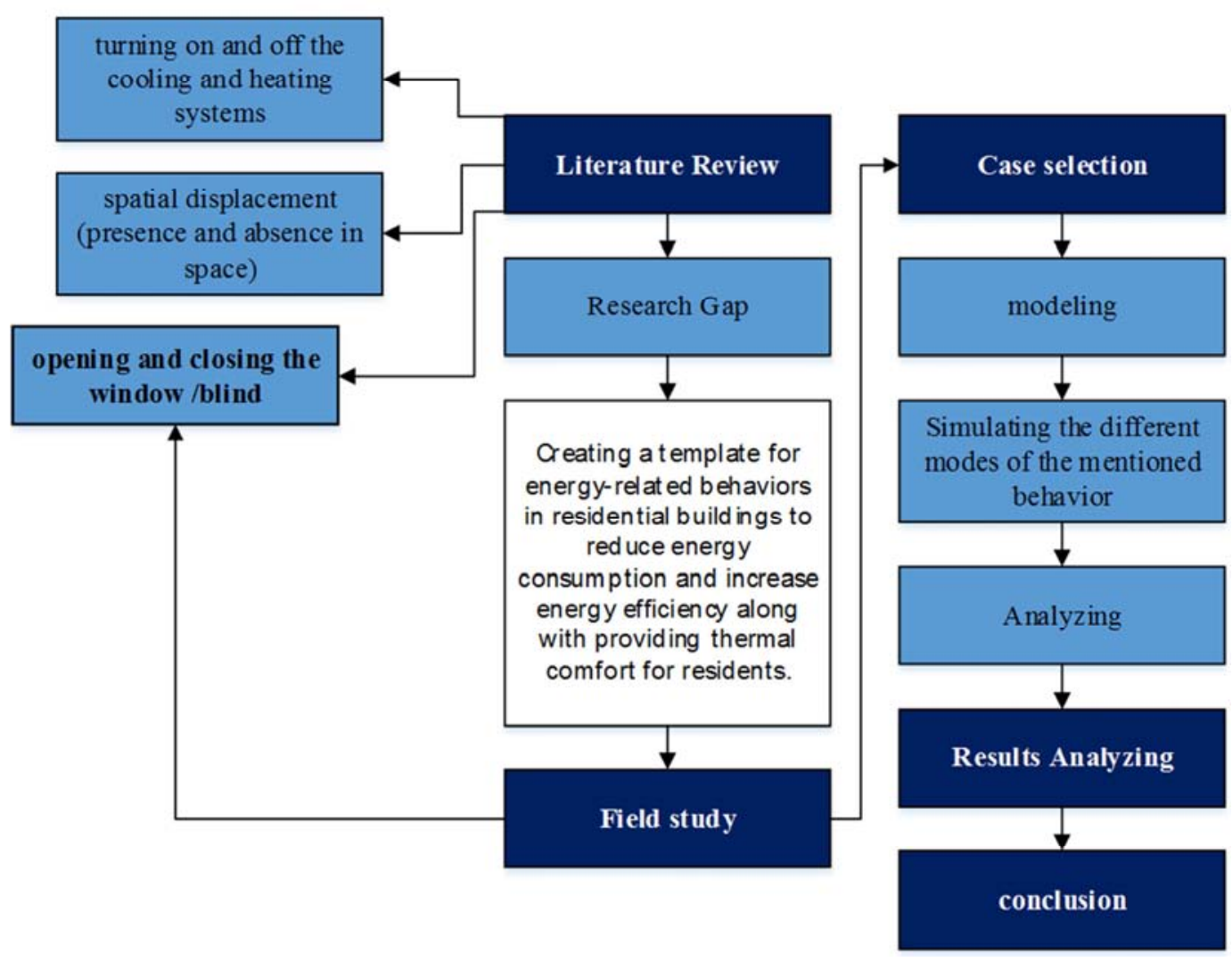

Figure 4. Research process. 


\subsection{Modeling Case Study - Simulation Energy-Related Behavior in Case Study}

\section{Assumption}

The studied sample was a unit of a five-floor apartment located in Gonbad-e Kavus, Golestan Province, with a warm and temperate climate. This was a complete example of most of the buildings in this town. The area of this unit was $165 \mathrm{~m}^{2}$ and a 4-story apartment is considered. The building orientation was northern-southern and the selected unit was southward. The fourth floor of this building was simulated in the software and the rest of floors were taken as uncontrollable space.

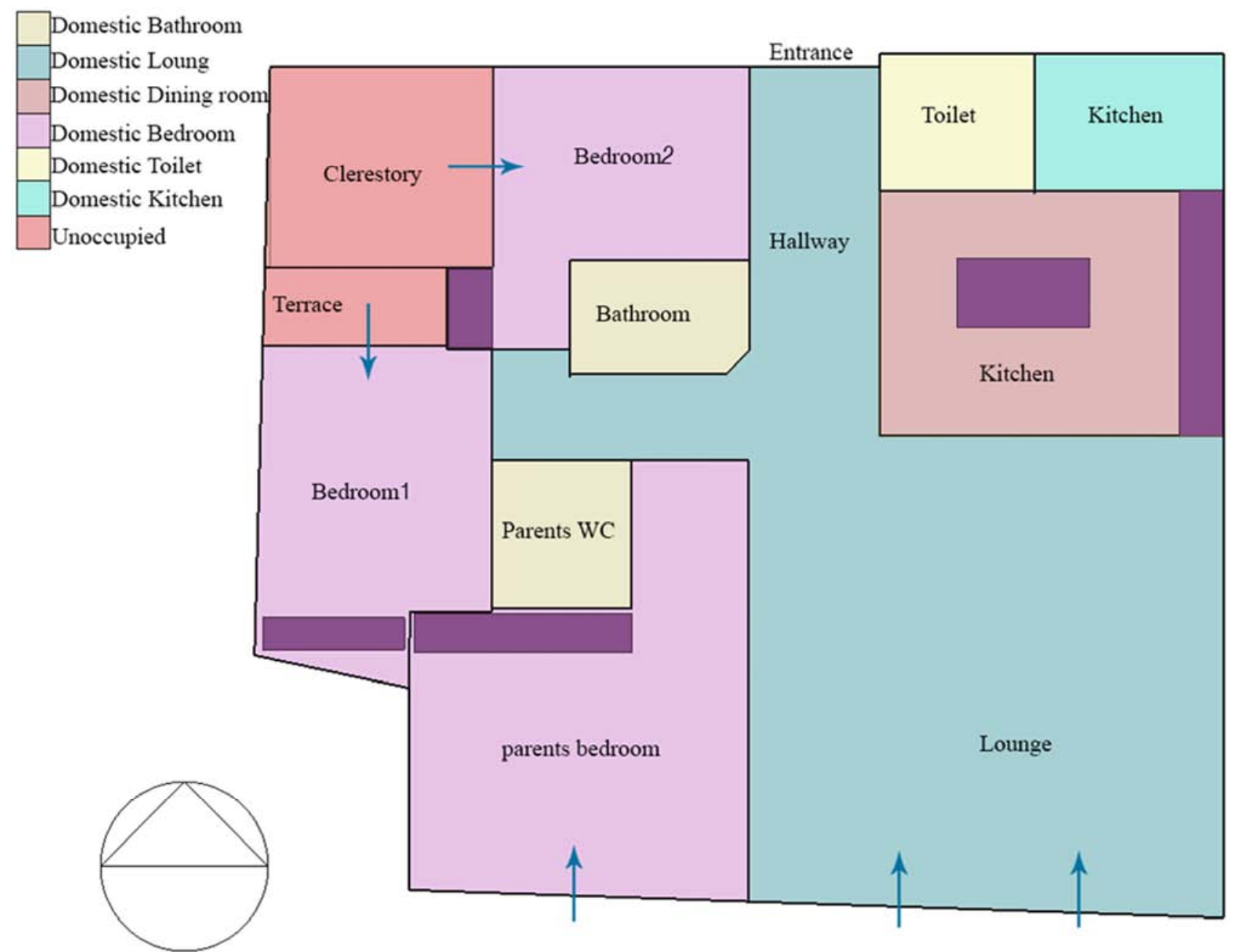

Figure 5. Simulated plan in design builder software.

The plan simulated in Design-Builder is shown in Figure 5 . The set point of for the system of cooling, heating, and natural ventilation were determined to be $26^{\circ}, 18^{\circ}$, and $25^{\circ}$. In overall, this plan consists of 5 windows, 2 internal windows and 3 external windows. External windows are embedded in the external wall and are southward and 2 internal ones, embedded in rooms, receive light and contribute in the ventilation. Also the arrows in the figure 3 represent the windows position in plan. According to assumptions, the simulation was done in three modes. In the first mode, the windows were considered inactive and curtains were taken active an all months of the year. In the second mode, windows were active and curtains were inactive during March, May, and June, when the ambient temperature is within the thermal comfort range of individuals. The status of windows and curtains were the same as the second mode but July, August, September, and part of October were added to the time mentioned for the second model. Considering the amount of humidity and wind, the ambient temperature in these months is at the threshold of tolerance and the windows were simulated active in the early and late hours of the day, when the intensity of radiation is less. The weight percentage during July, August, and September that windows are active is less than the time windows are in the second mode. This is due to the higher ambient temperature compared to the second mode. The windows are active in $80-85 \%$ of the time in the second mode, while this figure is equal to $50-60 \%$ in the third mode. This means that the windows are active (open) in $50-60 \%$ of an hour. Table 1 shows the hypothesized program for simulation. Other assumptions of this simulation included the opening direction and opening percentage. In all simulation 
modes, the opening direction was to the left and the opening percentage was 100. These assumptions were also applied to all internal windows. The material and type of curtains were considered the same for all windows in all three modes.

Table 1. Simulated application for windows and curtains in the assumed model.

\begin{tabular}{|c|c|c|c|c|c|c|}
\hline Type of Behavior & NO & Operation & Active months & $\begin{array}{l}\text { Outside temperature } \\
\left(\mathrm{C}^{\circ}\right)\end{array}$ & $\begin{array}{l}\text { Humidity } \\
(\%)\end{array}$ & Window type \\
\hline \multirow{2}{*}{$\begin{array}{l}\text { Opening and closing } \\
\text { window/blind }\end{array}$} & 1 & $\begin{array}{l}\text { 1. Window inactive } \\
\text { 2. blind active }\end{array}$ & $\begin{array}{l}\text { The window is considered inactive } \\
\text { for all months of the year } \\
\text { The blind is considered active for } \\
\text { all months of year }\end{array}$ & $18-29$ & $70 \%$ & $\begin{array}{l}\text { Whole interior and } \\
\text { exterior windows }\end{array}$ \\
\hline & 2 & $\begin{array}{l}\text { 1. Window active } \\
\text { 2. Blind inactive }\end{array}$ & March, April, June & $18-29$ & $70 \%$ & $\begin{array}{l}\text { Whole interior and } \\
\text { exterior windows }\end{array}$ \\
\hline
\end{tabular}

\section{Discussion and Results}

The ultimate aim of this study is to recognize the influences of the occupant behavior on the building energy consumption. According to $\mathrm{Yu}$ et al appraising building energy saving potential by improving the behavior of residents and provide multifaceted insights into building energy end-use patterns associated with the occupant behavior [21]. In addition according to Hoes et al due to increasing requisition for sustainable buildings, more passive building will be built, so the importance of the user behavior on the energy equivalence of a building increases. In the design phase through building performance simulation, this effect has only recently been recognized [22]. Hence In order to evaluate the cooling load and power consumption in the three simulated modes, the cooling load and power consumption merely for cooling were included in the simulation. In addition, the simulation results are presented on an annual basis. The results of simulation are given in table 2 , in the column of annual cooling load it can be seen that, the third mode has a lower cooling load compared to the other two modes. The cooling load for third, second, and first modes is equal to $-4251 \mathrm{~kW} / \mathrm{h},-5852$ $\mathrm{kW} / \mathrm{h}$, and $-6373 \mathrm{~kW} / \mathrm{h}$, respectively. As shown in Table 3, the cooling load optimization rate in the third mode is equal to $27.35 \%$ and $33.29 \%$, compared to the second and first mode, respectively. This indicates an increase of $10 \%$ in optimization between the first and second modes. On the other hand, the optimization rate of the second mode compared to the first mode is $5.51 \%$, which is the lowest figure in this regard. As regards Table 2 shows the amount of power consumed for cooling over one year for each of the three behavioral modes. According to this graph, the power consumed for cooling in the third mode is equal to $2796 \mathrm{~kW} / \mathrm{h}$. This figure increases to $3189 \mathrm{~kW} / \mathrm{h}$ and 3544 $\mathrm{kW} / \mathrm{h}$ for the second and first modes, respectively. Increased supposed months for more activity of simulated energy-related behavior had a direct impact on the amount of power consumed to provide cooling and thermal comfort. According to the values obtained for the amount of power consumed during one year, the highest percentage of optimization for annual power consumption was observed in the comparison between the third and first modes, which is $21.1 \%$ for one year. This figure reduces to $16.9 \%$ in the comparison between the second and third modes. The lowest percentage of optimization $(9.1 \%)$ is related to the first and second modes. According to the results and as well as figures 5 and6, the positive activity of simulated behavior has a favorable impact on energy efficiency figure.

Table 2. Zone sensible cooling \&electricity consumed.

\begin{tabular}{lll}
\hline NO & Annual cooling load & Annual power consumption \\
\hline 1 & -6373 & 3544 \\
2 & -5852 & 3189 \\
3 & -4251 & 2796 \\
\hline
\end{tabular}

Table 3. Optimization percentages from simulated states.

\begin{tabular}{lll}
\hline NO & $\begin{array}{l}\text { Percentage annual cooling } \\
\text { load }\end{array}$ & $\begin{array}{l}\text { Percentage annual power } \\
\text { optimization }\end{array}$ \\
\hline 1 & relative to first mode $\% 5 / 5$ & relative to first mode $\% 9 / 1$ \\
& relative to first mode $\% 33 / 29$ & $\begin{array}{l}\text { relative to first mode } \% 21 / 10 \\
\text { relative to second } \\
2\end{array}$ \\
relative to second & mode $\% 16 / 90$ \\
\hline
\end{tabular}

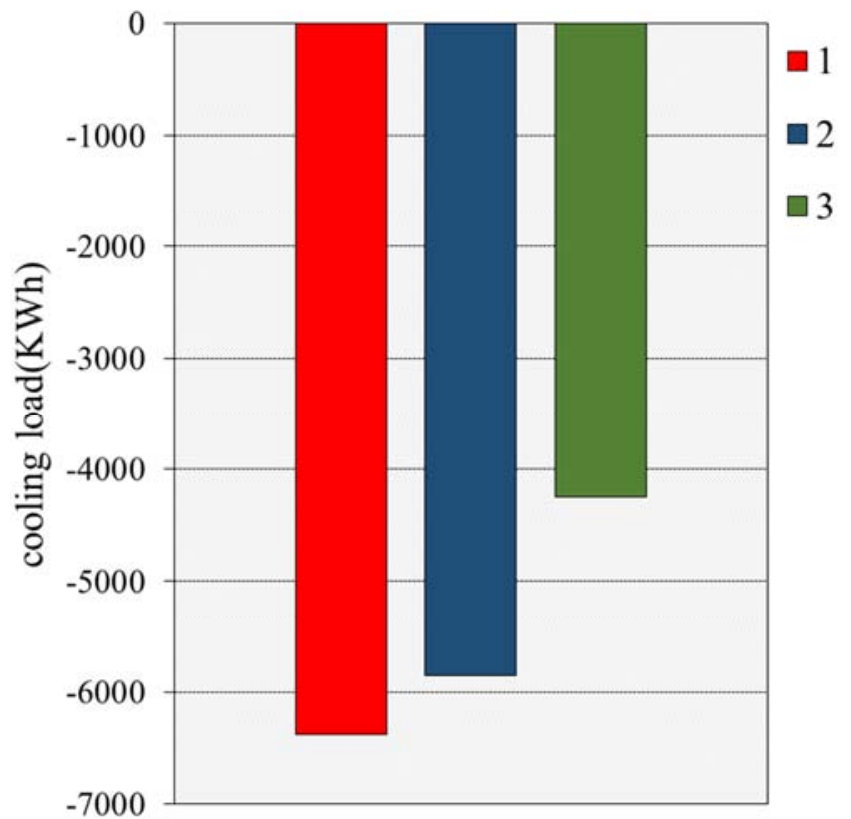

Figure 6. Zone sensible cooling in one year. 


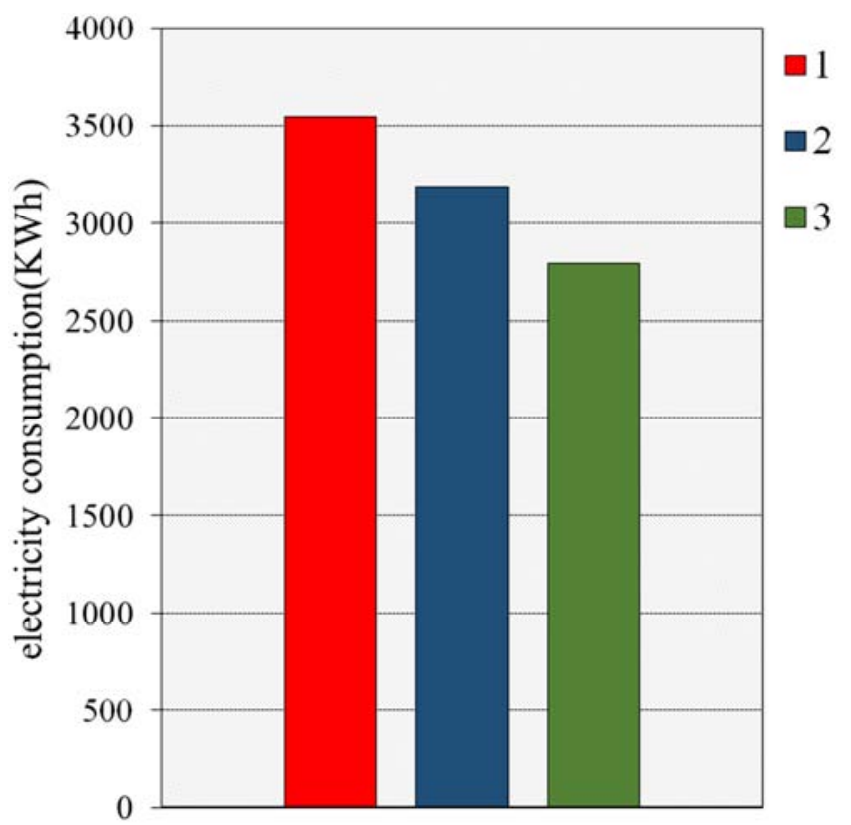

Figure 7. Electricity consumed in one year.

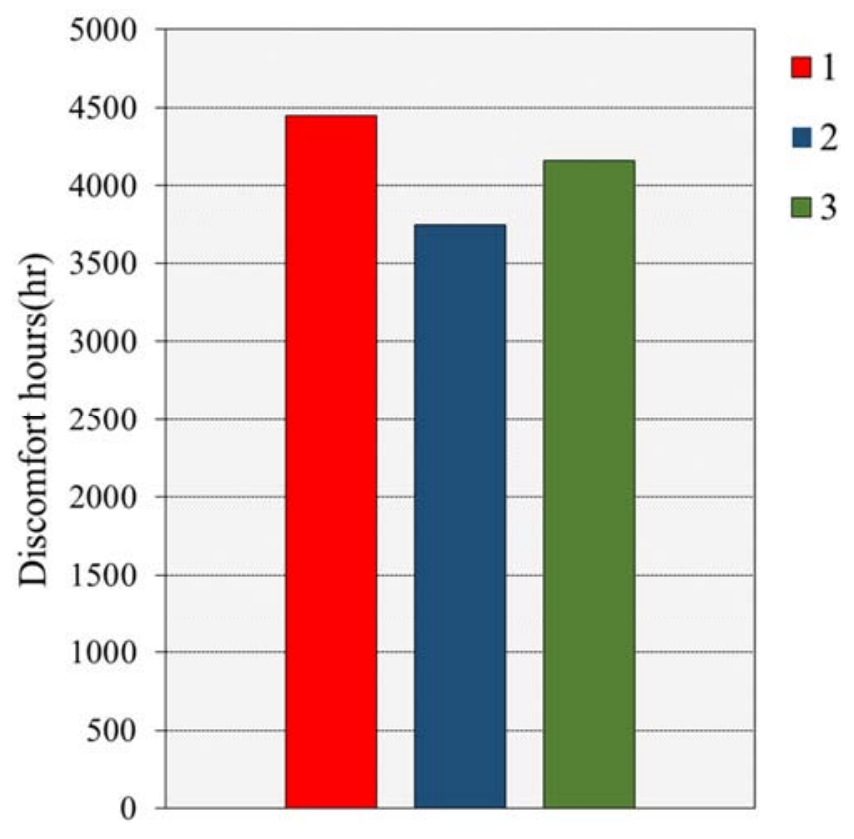

Figure 8. Discomfort hours in one year.

Figure 8 represents the total hours of dissatisfaction with thermal comfort during one year in all three modes. According to this graph, the highest dissatisfaction with thermal comfort is related to the first mode, in which the windows are considered closed in all months of the year and only mechanical systems were assumed to be used to create thermal comfort. In addition, the hours of dissatisfaction with thermal comfort in the second mode was lower than then the third mode, with a reduction of $20.44 \%$. Although the number of months with open windows in the second mode was lower than the third mode, dissatisfaction with thermal comfort was lower in the second mode. This suggests that how much opening the windows at the right time can be effective in providing thermal comfort and consequently reduces the use of mechanical systems. This greatly helps to reduce energy consumption.

\section{Conclusion}

Based on the study results (on only one energy-related behavior), it can be concluded that the first behavioral mode is the most suitable pattern for optimizing energy consumption. The highest energy consumption reduction (power consumption for cooling) was related to the third mode. Considering the slight difference between the third and second modes in terms of dissatisfaction with thermal comfort, the third mode is the most appropriate for the desired energy-related behavior. This amount of energy saving was achieved by changing the pattern of only one energy-related behavior. Furthermore, simpler measures, such as the correct use of curtains which serve as a canopy in today's homes, can be taken in order to both maintain the thermal comfort of individuals and increase energy efficiency. A reduction of $33.29 \%$ in power consumption and a reduction of $80.9 \%$ in dissatisfaction with thermal comfort in the third behavioral mode compared to the first mode indicate the significance of taking into account energy-related behaviors in the design and even post-construction stages. Hence, other energy-related behaviors and their effects on the reduction of energy consumption are recommended to be studied in future research in order to propose optimal patterns of these behaviors. The findings of such studies can be applied by the relevant organizations involved in the planning and culture-building of energy consumption. Moreover, some other factors such as the number of windows, area, location and direction, features and materials, and the size of canopies and curtains affect the application of windows. Since the present study was conducted in a building with common conditions, it should be noted that energy-related behaviors can have much greater effects on energy consumption optimization and thermal comfort in case of proper building design. In addition, building designers and constructors are recommended to pay a special attention to items such as determination of the optimal number and area of windows, appropriate openings, proper location and direction of windows, and optimal features for canopies and curtains. All these issues increase the efficiency of windows, as an external factor involved with energyrelated behaviors, in line with the improvement of energy efficiency and thermal comfort. As previously mentioned, a few studies have been conducted about energy-related behaviors and their impacts, which have mainly focused on the proposal of optimal behavioral patterns based on cultural backgrounds and features of the target community. Hence, the study of this issue in Iran involves different features, priorities, and patterns. However, the results of the present study somewhat corroborate the effects of energy-related behaviors on the reduction of energy consumption reported in previous studies. On the other hand, typical features of a building such as the number and area of windows and position of openings and canopies, along with the cultural 
issues of Iranian society (e.g. confidentiality and overlooking), is an interesting area of research. In general, it can be stated that energy-related behaviors, besides other construction and technical solutions, have a very high potential for the optimization of energy consumption in buildings. In addition, these behaviors increase the involvement of users, as part of the building, in the reduction of environmental impacts of energy consumption. On the other hand, identification, definition, and proposal of optimal patterns for all kinds of energy-related behaviors in residential buildings based on the climatic and environmental conditions and cultural contexts of a community can be the subject of future studies in this field.

\section{References}

[1] G. M. Huebner, I. Hamilton, Z. chalabi, D. Shipworth and T. Oreszczyn, "Explaining domestic energy consumption-The comparative contribution of building factors, sociodemographics, behaviours and attitudes," Applied Energy, vol. 159, pp. 589-600, 2015.

[2] D. Yan, T. Hong, B. Dong, A. Mahdavi, S. D Oca, I. Gaetani and X. Feng, "IEA EBC Annex66:Definition and simulation of occupant behavior in buildings," Energy and Buildings, vol. 156, pp. 258-270, 2017.

[3] I. Blom, L. Itard and A. Meijer, "Environmental impact of building-related and user-related energy consumption in dwellings," Building and Environmet, vol. 46, pp. 1657-1669, 2011.

[4] L. Swan and V. Ugursal, "Modeling of end-use consumption in the residential sector: Areview of modeling techniques," Renewable and Sustainable Energy Reviews, vol. 13, pp. 1819-1835, 2009.

[5] T. Dietz, P. C. Stren and E. U. Weber, "Reducing carbon-based energy consumption through changes in household behavior," The American Academy of Arts\& Sciences, vol. 142, pp. 7889, 2013.

[6] "The World Bank IBRD.IDA. CO2 Emissions (metric tons per capita)," [Online]. Available:

http://data.worldbank.org/indicator/EN.ATM.CO2E.PC; 2015 (Accessed 16.05.02).

[7] D. Zhao, A. Mccoy, J. Du, P. Agee and Y. Lu, "Intraction effects of building technology and resident behavior on energy consumption in residential buildings," Energy and Buildings, vol. 134, pp. 223-233, 2017.

[8] T. Hong, S. D "Oca, W. J. Turner and S. Taylor-Lange, "An ontology to represent energy-related occupant behavior in buildings. Part 1: Introducing to the DNAs framework," Building and Environment, vol. 92, pp. 764-777, 2015.

[9] T. Hong, S. D Oca, S. Taylor-Lange, W. J. Turner, Y. Chen and S. Corgnati, "An ontology to represent energy-related occupant behavior in buildings. Part 2: Implementation of the
DANs framework using an XML schema," Building and Environment, vol. 94, pp. 196-205, 2015.

[10] K. Sun and T. Hong, "A simulation approach to estimate energy saving potential of occupant behavior measures," Energy and Buildings, vol. 136, pp. 43-62, 2017.

[11] D. Yan, W. O"Brien, T. Hong, X. Feng, H. Gunay, F. Tahmasebi and A. Mahdavi, "Occupant behavior modeling for building performance simulation: cuurent state and future challenges," Energy and Buildings, vol. 107, pp. 264-278, 2015.

[12] C. Hiller, "Factors influencing residents energy use-A study of energy-related behavior in 57 Swedish homes," Energy and Buildings, vol. 87, pp. 243-252, 2015.

[13] F. Stazi, F. Naspi and M. D "Orazio, "A literture review on driving factors and contextual events influencing occupants behaviors in buildings," Building and Environment, vol. 118, pp. 40-66, 2017.

[14] K. Sun and T. Hong, "A farmework for quantifying the impact of occupant behavior on energy savings of energy conservation measures," Energ and Buildings, vol. 146, pp. 383-396, 2017.

[15] E. Delzendeh, S. Wu, A. Lee and Y. Zhou, "The impact of occupant $\mathrm{s}$ behaviors on building energy analysis: A research review," Renewable and sustainable energy reviews, vol. 80, pp. 1061-1071, 2017.

[16] M. Yao and B. Zhao, "Window opening behavior of occupants in residential buildings in Beijing," Building and Environment, vol. 124, pp. 441-449, 2017.

[17] J. Kim, T. Hong, J. Jeong, M. Lee, K. Jeong, C. Koo and J. Jeong, "Establishment of an optimal occupant behavior considering the energy consumption and indoor environmental quality by region," Applied Energy, vol. 204, pp. 1431-1443, 2017.

[18] T. Hong, S. Taylor-Lang, S. D Oca, D. Yan and S. Corgnati, "Advances in research and applications of energy-related occupant behavior in buildings," Energy and Buildings, vol. 116, pp. 694-702, 2016.

[19] M. Vellei, S. Natarajan, B. Bin, J. Padget and I. Walker, "The effect of real-time context-aware feedback on occupants heating behavior and thermal adaption," Energy and Buildings, vol. 123, pp. 179-191, 2016.

[20] Z. Zomordian and M. Tahsildoost, "Validation of energy simulation software in the building, with an empirical and comparative approach (in persian)," Energy, vol. 56, pp. 115$132,2015$.

[21] Z. Yu, B. Fung, H. Friborz, H. Yoshino and E. Morofsky, "A systematic procedure to study the influence of occupant behavior on building energy consumption," Energy and Buildings, vol. 43, pp. 1409-1417, 2011.

[22] P. Hoes, J. Hensen, M. Loomans, B. d. Vries and D. Bourgeois, "User behavior in whole building simulation," Energy and Buildings, vol. 41, pp. 295-302, 2009. 